\title{
Degradabilidade no rúmen bovino de grãos de milho processados de diferentes formas
}

\author{
Roberta Passini ${ }^{(1)}$, Laura Maria Oliveira Borgatti(2), Fernanda Altieri Ferreira ${ }^{(1)}$ \\ e Paulo Henrique Mazza Rodrigues ${ }^{(1)}$
}

(1)Universidade de São Paulo (USP), Faculdade de Medicina Veterinária e Zootecnia (FMVZ), Dep. de Nutrição e Produção Animal, Caixa Postal 23, CEP 13630-970 Pirassununga, SP. E-mail: rpassini@usp.br, faltieri@usp.br, pmazza@usp.br (2)USP, Centro de Energia Nuclear na Agricultura, Laboratório de Nutrição Animal, Caixa Postal 96, CEP 13400-970 Piracicaba, SP. E-mail: uaiborgatti@yahoo.com

\begin{abstract}
Resumo - O objetivo deste trabalho foi avaliar o efeito de formas de processamento de milho na degradabilidade da matéria seca, amido e proteína em rúmen de bovinos. Foram utilizadas 12 fêmeas bovinas mestiças, não gestantes e não lactantes, portadoras de cânulas ruminais e com peso médio de $647 \mathrm{~kg}$. Foi utilizado um delineamento inteiramente casualizado com três tratamentos: quebra $(1,6 \mathrm{~mm})$, moagem fina $(0,8 \mathrm{~mm})$ e floculação $(8,25 \mathrm{~mm} ; 270 \mathrm{~g} / \mathrm{L})$ dos grãos de milho, com 4 repetições por tratamento. Os sacos de náilon contendo milho nos diferentes processamentos foram incubados nos animais durante $0,1,5,3,6,12,24$ e 48 horas. Foi observado aumento na degradabilidade efetiva da matéria seca e do amido do milho pela floculação, em relação à moagem fina e à quebra. Contudo, a degradabilidade efetiva da proteína do milho foi diminuída pela floculação, em relação à moagem fina.
\end{abstract}

Termos para indexação: Zea mays, digestão ruminal, ruminantes.

\section{Degradability of differently processed corn grain in bovine rumen}

\begin{abstract}
The objective of this paper was to evaluate the effect of different forms of processing corn on ruminal degradability of dry matter, starch and crude protein. Twelve non-lactant and non-pregnant canulated cows $(647 \mathrm{~kg})$ were used. Experimental design was completely randomized with three treatments: cracked $(1.6 \mathrm{~mm})$, grinding $(0.8 \mathrm{~mm})$ and steam-flaked $(8.25 \mathrm{~mm} ; 270 \mathrm{~g} / \mathrm{L})$ corn, with 4 experimental units/treatment. Bags containing corn in different processing forms were incubated in animals for $0,1.5,3,6,12,24$ and 48 hours. An improvement on effective dry matter and starch degradability by the steam-flaked compared to grinding and cracked corn was observed. However, a decrease in crude protein degradability for steam-flaked compared to grinding corn was also observed.
\end{abstract}

Index terms: Zea mays, ruminal digestion, ruminants.

\section{Introdução}

Os grãos são componentes predominantes nas dietas de bovinos, e o amido representa $60-80 \%$ desse grão (Kotarski et al., 1992; McCleary et al., 1994). O grau de processamento e a espécie do grão influenciam o sítio e a extensão da sua digestão pelos ruminantes (Owens et al., 1986).

O processamento do milho aumenta a utilização do amido, in vitro, in situ e in vivo em virtude da melhora da fermentação ruminal e da digestão intestinal (Theurer, 1986). A floculação do milho causa gelatinização do amido, por meio da ruptura das pontes de hidrogênio intermoleculares, e aumenta a superfície do grão sujeita ao ataque microbiano, resultando em maior digestão ruminal do amido (Rooney \& Pflugfelder, 1986).
O tratamento pelo calor desnatura a proteína pela alteração na sua estrutura tridimensional, e, quando aplicado excessivamente, ocasiona a formação de reações de Maillard, ou seja, ligações entre proteínas e carboidratos resistentes à protease (Cheftel et al., 1976).

Além do processamento, o tamanho de partícula influencia os padrões de fermentação ruminal, produção microbiana e eficiência da utilização do amido e outros nutrientes no rúmen. Entretanto, segundo Cone et al. (1989), o impacto da floculação sobre a degradabilidade do amido é maior do que os efeitos da moagem dos grãos.

Teixeira et al. (1996), estudando a degradabilidade in situ do milho moído e quebrado, concluíram que a degradabilidade efetiva da matéria seca e a taxa de de- 
gradação foram superiores na forma moída, numa taxa de passagem de 5\% por hora. Sindt et al. (1993) estudaram dietas à base de milho quebrado ou sorgo finamente moído para novilhos e observaram que a taxa de desaparecimento do amido e a extensão da digestão às 12 e 18 horas foi maior no sorgo finamente moído do que no milho quebrado $(\mathrm{P}<0,01)$.

O objetivo deste trabalho foi avaliar o efeito de diferentes formas de processamento de grãos de milho na degradabilidade da matéria seca, amido e proteína em rúmen de bovinos.

\section{Material e Métodos}

Um estábulo, consistindo de baias com cochos individuais e bebedouros automáticos comuns a cada dois animais, foi usado como instalação experimental. Foram utilizadas 12 fêmeas bovinas mestiças holandês $\mathrm{x}$ zebu, não lactantes e não gestantes, possuindo em média $647 \mathrm{~kg}$ de peso vivo e portadoras de cânulas ruminais.

A ração, fornecida às 8 e 16 horas, foi composta por cana picada, uréia e grãos de milho processado em três diferentes formas compondo os tratamentos, na proporção de $70 \%$ de concentrado. Foram coletadas amostras diárias da dieta durante o período experimental para análises bromatológicas, as quais foram realizadas pelo Laboratório de Bromatologia da Faculdade de Medicina Veterinária e Zootecnia da Universidade de São Paulo, segundo Association of Official Analytical Chemists (1985). A composição química dos ingredientes usados para compor as dietas consta da Tabela 1. A porcentagem dos ingredientes nas diferentes dietas assim como sua composição química são apresentadas na Tabela 2.
Utilizou-se um delineamento inteiramente casualizado com três tratamentos correspondendo às formas de processamento do milho: moagem grossa $(1,6 \mathrm{~mm}$ de tamanho médio ponderado de partícula); moagem fina (0,8 mm) e floculação $(8,25 \mathrm{~mm}$ e densidade $270 \mathrm{~g} / \mathrm{L})$.

A moagem grossa do milho foi obtida em moinho de martelo sem peneira, o que promoveu a quebra do grão em 3 a 4 partes. A moagem fina consistiu na moagem comum em peneira de $0,2 \mathrm{~mm}$, originando o fubá de milho. O milho floculado, proveniente da Fábrica Ração Total, foi obtido pelo método de floculação a vapor, com uma temperatura máxima de secagem de $46,7^{\circ} \mathrm{C}$ em queimador a gás, originando um produto final com $260 \mathrm{a}$ $280 \mathrm{~g} / \mathrm{L}$.

O ensaio de degradabilidade in situ foi realizado segundo Mehres \& Ørskov (1977). Utilizaram-se sacos de náilon, com porosidade de 50 micras, medindo $10,0 \times 19,0 \mathrm{~cm}$ que abrigaram cerca de $10 \mathrm{~g}$ das amostras dos alimentos, previamente secadas em estufa a $65^{\circ} \mathrm{C}$ por 72 horas e processadas conforme descrito anteriormente. Os sacos foram pesados em balança analítica de precisão e, após serem amarrados, foram armazenados em câmara fria até o momento do uso. Os sacos foram incubados nos animais durante $0,1,5,3$, $6,12,24$ e 48 horas.

Retirados do rúmen, os sacos foram lavados em água corrente até o líquido de lavagem fluir incolor, sendo levados à estufa sob $65^{\circ} \mathrm{C}$ por 72 horas, para posterior pesagem e análise bromatológica. A degradabilidade em tempo zero foi tomada mergulhando-se os sacos em recipiente contendo água à temperatura de $39^{\circ} \mathrm{C}$ durante 15 minutos (Cummins et al., 1983). Os dados de degradabilidade foram ajustados pelo modelo de Ørskov \& McDonald (1979). A degradabilidade potencial (Dp) e a degradabilidade efetiva (De) foram calculadas pela

Tabela 1. Composição química (\%) dos ingredientes usados para compor as dietas de vacas mestiças, com base na matéria seca.

\begin{tabular}{|c|c|c|c|c|}
\hline Composição & Cana-de-açúcar & Milho quebrado & Milho moído fino & Milho floculado \\
\hline Matéria seca total & 97,52 & 90,03 & 88,91 & 88,26 \\
\hline Proteína bruta & 2,83 & 10,17 & 9,46 & 9,13 \\
\hline Extrato etéreo & 0,66 & 4,97 & 4,63 & 2,67 \\
\hline Fibra bruta & 27,89 & 1,44 & 1,04 & 1,19 \\
\hline Fibra em detergente neutro & 55,60 & 12,68 & 11,43 & 13,08 \\
\hline Fibra em detergente ácido & 37,26 & 7,26 & 5,87 & 8,58 \\
\hline Lignina & 6,18 & 1,59 & 1,20 & 1,13 \\
\hline Amido & - & 65,75 & 65,16 & 67,18 \\
\hline Matéria mineral & 2,39 & 1,36 & 1,43 & 0,20 \\
\hline Cálcio & 0,09 & 0,02 & 0,05 & 0,02 \\
\hline Fósforo & 0,04 & 0,32 & 0,30 & 0,17 \\
\hline
\end{tabular}


fórmula de Ørskov et al. (1980). O amido foi analisado pelo método de Rossi Júnior \& Pereira (1995), procedendo-se a extração prévia dos carboidratos solúveis, segundo Hendrix (1993).

Os dados foram analisados pelo programa Statistical Analysis System (SAS Institute, 1985), sendo verificada a normalidade dos resíduos e a homogeneidade das variâncias. Os dados que não atenderam a estas premissas foram submetidos à transformação logarítmica $[\log (x+1)]$ ou pela raiz quadrada $\left[(x+0,5)^{0,5}\right]$. Os dados originais ou transformados, quando este procedimento foi necessário, foram submetidos à análise de variância pelo procedimento General Linear Models (PROC GLM) e as médias comparadas pelo teste de Tukey. Adotou-se um nível de significância de 5\% para os parâmetros analisados.

\section{Resultados e Discussão}

Constatou-se maior fração solúvel em relação à floculação, seguida da moagem fina e da quebra dos grãos de milho (Tabela 3). Contudo, Lykos \& Varga (1995), estudando degradação in situ da matéria seca (MS) do milho, não encontraram diferença na fração solúvel entre milho floculado e milho moído finamente, observando o menor valor para quebra.

Considerando taxas de passagem de $5 \%$ e $8 \%$ /hora, a degradabilidade efetiva da matéria seca do milho foi decrescente em relação à floculação, moagem fina e quebra, respectivamente (Tabela 4). Considerando uma taxa de passagem de 5\%/hora, a floculação aumentou a degradabilidade da matéria seca do milho em 19,07\% ou 10,21 UP (unidades porcentuais) em relação à moagem fina, e ocasionou um aumento de $54,43 \%$ ou 22,47 UP em relação à quebra do grão $(\mathrm{P}<0,01)$. Entretanto, para taxa de passagem estimada de $2 \%$ /hora não foi observada diferença entre floculação e moagem fina sobre a degradabilidade da matéria seca do milho. Wadhwa et al. (1998), trabalhando com búfalos, observaram uma redução linear na degradabilidade efetiva da MS do milho com o aumento do tamanho de partícula. O aumento da granulometria de $1 \mathrm{~mm}$ para 2,5 mm reduziu em 10,4\% a degradação da MS, em uma taxa de passagem de 5\%/hora. Passini (2001) reportou aumento na degradabilidade efetiva da MS do milho moído finamente (fubá) em 40,2\%, em relação ao milho quebrado.

Lee et al. (2002), estudando a digestibilidade in vitro da MS do milho, reportaram valores de 90,31, 76,48 e $61,68 \%$ em relação aos processamentos de moagem fina $(1 \mathrm{~mm})$, quebra $(4 \mathrm{~mm})$ e floculação, respectivamente; no estudo in situ, os resultados foram semelhantes aos obtidos in vitro para os diferentes processamentos.

Lykos \& Varga (1995), estudando a digestão ruminal do milho, obtiveram valores de degradação efetiva da MS em relação à floculação de $65,9 \%$, semelhante ao obtido neste trabalho $(63,75 \%)$. Entretanto, a moagem fina, contrariamente aos resultados observados, apresentou valor semelhante ao da floculação $(62,7 \%)$, ficando a quebra com $41,5 \%$ (taxa de passagem de $5 \%$ /hora).

Tabela 2. Porcentagem dos ingredientes e composição química das dietas de vacas mestiças, como porcentagem da matéria seca.

\begin{tabular}{lccc}
\hline Ingredientes & Milho quebrado & Milho moído fino & Milho floculado \\
\hline Cana-de-açúcar & 31,27 & 31,29 & 31,28 \\
Milho quebrado & 67,07 & - & - \\
Milho moído fino (fubá) & - & 67,06 & - \\
Milho floculado & - & - & 67,06 \\
Uréia & 0,52 & 0,52 & 0,52 \\
Sal branco & 0,10 & 0,10 & 0,10 \\
Mistura mineral ${ }^{(1)}$ & 1,04 & 1,03 & 1,04 \\
\hline & & Composição química & 52,10 \\
Matéria seca & 52,50 & 52,20 & 11,36 \\
Proteína bruta & 11,55 & 10,99 & 17,41 \\
Fibra em detergente ácido & 16,52 & 15,59 & 26,57 \\
Fibra em detergente neutro & 25,89 & 25,06 & 46,29 \\
Amido & 45,32 & 44,95 & 1,61 \\
Energia líquida para lactação $(\mathrm{Mcal} / \mathrm{kg})^{(2)}$ & 1,52 & 1,61 & 0,23 \\
Cálcio & 0,23 & 0,25 & 0,22 \\
Fósforo & 0,32 & 0,31 & \\
\hline
\end{tabular}

${ }^{(1)}$ Níveis de garantia por quilograma do produto: P, 80 g; Ca, 150 g; S, 12 g; Zn, 4.500 mg; Cu, 1.600 mg; Co, 210 mg; Mn, 1.400 mg; I, 180 mg; Se, 27 mg; Ni, 11 mg; F, 1,3 g; Cl, 228 g; Na, 144,40 g. (2)Estimada conforme National Research Council (1989). 
Em relação ao amido foi observada maior fração solúvel para o milho floculado, seguido da moagem fina e da quebra. A degradabilidade efetiva do amido foi superior no milho floculado em todas as taxas de passagem estimadas. A degradabilidade efetiva do amido foi aumentada pela floculação em $32,47 \%$ ou $17,66 \mathrm{UP}$ em relação ao milho moído fino, e $62,51 \%$ ou 27,71 UP em relação ao milho quebrado, na taxa de passagem de $5 \%$ /hora $(\mathrm{P}<0,01)$.
Theurer (1986), revisando estudos sobre a degradação ruminal do amido do milho em diferentes processamentos com ovinos, reportou valores de degradação ruminal de $78 \%$ para milho quebrado e $82 \%$ para o floculado, ou seja, um aumento de $5,13 \%$, bastante inferior ao encontrado no presente trabalho $(62,51 \%)$. Theurer et al. (1999), em recente revisão, relataram que a floculação resultou em um aumento na digestão ruminal do amido de $49 \%$ em relação ao milho quebrado (52\%

Tabela 3. Degradabilidade em rúmen de vacas mestiças, da matéria seca, do amido e da proteína bruta do milho, sob diferentes formas de processamento $^{(1)}$.

\begin{tabular}{|c|c|c|c|c|c|c|}
\hline Nutriente & Milho quebrado & Milho moído fino & Milho floculado & Média & $\mathrm{CV}(\%)$ & Probabilidade \\
\hline & & \multicolumn{5}{|c|}{ Fração solúvel (\%) } \\
\hline Matéria seca & $8,05 \mathrm{c}$ & $13,09 \mathrm{~b}$ & $29,17 \mathrm{a}$ & 17,10 & 58,31 & 0,0001 \\
\hline Amido & $9,91 b$ & $13,42 b$ & $35,06 \mathrm{a}$ & 19,46 & 62,71 & 0,0001 \\
\hline \multirow[t]{2}{*}{ Proteína bruta } & $11,31 \mathrm{~b}$ & $18,07 \mathrm{a}$ & $15,67 \mathrm{a}$ & 15,02 & 24,70 & 0,0129 \\
\hline & & \multicolumn{5}{|c|}{ Fração potencialmente degradável (\%) } \\
\hline Matéria seca & $94,19 \mathrm{a}$ & $89,70 \mathrm{a}$ & $68,70 \mathrm{~b}$ & 83,70 & 16,21 & 0,0021 \\
\hline Amido & $81,99 \mathrm{a}$ & $90,97 \mathrm{a}$ & $66,10 \mathrm{~b}$ & 79,69 & 14,59 & 0,0002 \\
\hline \multirow[t]{2}{*}{ Proteína bruta } & $70,21 \mathrm{a}$ & $84,36 a$ & $55,70 \mathrm{a}$ & 70,09 & 25,97 & $\mathrm{~ns}$ \\
\hline & & \multicolumn{5}{|c|}{ Taxa de degradação $(\% / \mathrm{h})$} \\
\hline Matéria seca & $0,028 \mathrm{a}$ & $0,043 \mathrm{a}$ & $0,056 \mathrm{a}$ & 0,042 & 48,13 & $\mathrm{~ns}$ \\
\hline Amido & $0,037 \mathrm{a}$ & $0,044 \mathrm{a}$ & $0,069 \mathrm{a}$ & 0,050 & 48,16 & ns \\
\hline \multirow[t]{2}{*}{ Proteína bruta } & $0,033 \mathrm{a}$ & $0,026 \mathrm{a}$ & $0,043 \mathrm{a}$ & 0,034 & 38,95 & $\mathrm{~ns}$ \\
\hline & & \multicolumn{5}{|c|}{ Degradabilidade efetiva $2 \%(2)$} \\
\hline Matéria seca & $62,27 b$ & $73,18 \mathrm{a}$ & $78,06 \mathrm{a}$ & 70,99 & 10,82 & 0,0002 \\
\hline Amido & $62,64 \mathrm{c}$ & $73,89 b$ & $84,87 \mathrm{a}$ & 73,80 & 14,06 & 0,0003 \\
\hline \multirow[t]{2}{*}{ Proteína bruta } & $54,86 \mathrm{ab}$ & $64,73 \mathrm{a}$ & $50,72 b$ & 56,77 & 14,85 & 0,0335 \\
\hline & & \multicolumn{5}{|c|}{ Degradabilidade efetiva $5 \%{ }^{(2)}$} \\
\hline Matéria seca & $41,28 \mathrm{c}$ & $53,54 b$ & $63,75 \mathrm{a}$ & 52,79 & 20,04 & 0,0001 \\
\hline Amido & $44,33 b$ & $54,38 \mathrm{~b}$ & $72,04 \mathrm{a}$ & 56,92 & 22,75 & 0,0002 \\
\hline \multirow[t]{2}{*}{ Proteína bruta } & $39,13 \mathrm{ab}$ & $46,25 \mathrm{a}$ & $38,59 \mathrm{~b}$ & 41,32 & 12,11 & 0,0333 \\
\hline & & \multicolumn{5}{|c|}{ Degradabilidade efetiva $8 \%{ }^{(2)}$} \\
\hline Matéria seca & $32,02 \mathrm{c}$ & $43,64 b$ & $56,07 \mathrm{a}$ & 43,93 & 25,60 & 0,0001 \\
\hline Amido & $35,48 b$ & $44,52 b$ & $64,64 a$ & 48,21 & 28,08 & 0,0001 \\
\hline \multirow[t]{2}{*}{ Proteína bruta } & $31,76 \mathrm{~b}$ & $38,29 \mathrm{a}$ & $32,78 b$ & 34,28 & 11,69 & 0,0498 \\
\hline & & \multicolumn{5}{|c|}{ Degradabilidade potencial } \\
\hline Matéria seca & $102,24 \mathrm{a}$ & $102,79 a$ & $97,87 \mathrm{a}$ & 100,80 & 6,56 & ns \\
\hline Amido & $91,90 b$ & $104,40 \mathrm{a}$ & $101,15 \mathrm{ab}$ & 99,15 & 7,03 & 0,0116 \\
\hline Proteína bruta & $81,53 \mathrm{~b}$ & $102,43 \mathrm{a}$ & $71,37 \mathrm{~b}$ & 85,11 & 21,69 & 0,0345 \\
\hline
\end{tabular}

(1)Letras iguais nas linhas não diferem entre si pelo teste de Tukey a $5 \%$ de probabilidade. (2)Degradabilidade efetiva para taxas de passagem iguais a $0,02,0,05$ e 0,08

Tabela 4. Relação entre a degradabilidade, em rúmen de vacas mestiças, do amido e da proteína do milho, sob diferentes formas de processamento $^{(1)}$.

\begin{tabular}{lcccccc}
\hline Degradabilidade ${ }^{(2)}$ & Milho quebrado & Milho moído fino & Milho floculado & Média & CV (\%) & Probabilidade \\
\hline DEA/DEP 2\% & $1,15 \mathrm{~b}$ & $1,14 \mathrm{~b}$ & $1,71 \mathrm{a}$ & 1,33 & 24,70 & 0,0249 \\
DEA/DEP 5\% & $1,14 \mathrm{~b}$ & $1,17 \mathrm{~b}$ & $1,87 \mathrm{a}$ & 1,40 & 27,07 & 0,0001 \\
DEA/DEP 8\% & $1,12 \mathrm{~b}$ & $1,16 \mathrm{~b}$ & $1,97 \mathrm{a}$ & 1,42 & 29,91 & 0,0001 \\
DPA/DPP & $1,13 \mathrm{a}$ & $1,02 \mathrm{a}$ & $1,52 \mathrm{a}$ & 1,22 & 26,80 & ns \\
\hline
\end{tabular}

(1)Letras iguais nas linhas não diferem entre si pelo teste de Tukey a 5\% de probabilidade. (2)Relação entre a degradabilidade efetiva do amido (DEA) e da proteína (DEP) para taxas de passagem iguais a 0,02, 0,05 e 0,08, e relação entre a degradabilidade potencial do amido (DPA) e da proteína (DPP). 
vs. 35\%), aumentando também a digestão pós-ruminal em $52 \%$ ( $93 \%$ vs. $61 \%$ ) e no trato total em $24 \%$ (97\% vs. $78 \%$ ).

Lykos \& Varga (1995) também obtiveram valores de degradação do amido superiores no milho floculado $(75,4 \%)$, seguido pelo milho moído fino $(64,5 \%)$ e pelo milho quebrado $(44,6 \%)$, observando aumentos na degradabilidade do amido proveniente da floculação de $16,9 \%$, em relação à moagem fina, e de $69,1 \%$ em relação à quebra. Segundo Rooney \& Pflugfelder (1986), a floculação causa gelatinização do amido (quebra da matriz protéica ao redor dos grânulos de amido e ruptura das pontes de hidrogênio intermoleculares) e aumenta a superfície do grão para o ataque microbiano, resultando em maior digestão ruminal do amido.

Não houve diferença na degradabilidade efetiva do amido entre a moagem fina e a quebra dos grãos de milho nas taxas de passagem de 5\% e 8\%/hora. Entretanto, com uma taxa de $2 \%$ /hora o milho moído fino apresentou maior degradabilidade efetiva do amido em relação ao milho quebrado.

A degradabilidade da fração solúvel da proteína não diferiu entre os processamentos de floculação e moagem fina e a quebra apresentou o menor valor. A degradabilidade efetiva da proteína, em relação às taxas de passagem de $2 \%$ e $5 \%$ /hora, foi superior no milho moído fino em relação ao floculado, verificandose valores intermediários na quebra. A floculação reduziu a degradabilidade da proteína em $16,56 \%$ ou 7,66 UP em relação ao milho fino, para uma taxa de passagem de 5\%/hora. Contudo, na taxa de passagem estimada de $8 \%$ /hora, a moagem fina foi superior aos demais processamentos. A floculação aumentou a relação entre a degradabilidade efetiva do amido e a da proteína, diminuindo a sincronia na disponibilização desses nutrientes no rúmen (Figura 1). Segundo Herrera-Saldana

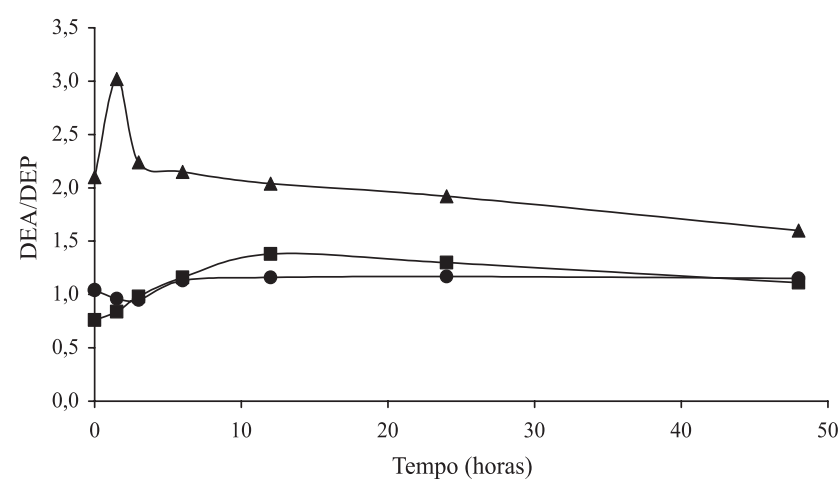

Figura 1. Relação entre a degradabilidade, em rúmen de vacas mestiças, do amido (DEA) e da proteína bruta (DEP) do milho quebrado (○), milho moído fino ( $\mathbf{(})$ e milho floculado $(\boldsymbol{\Lambda})$, ao longo do experimento. et al. (1990), é de extrema importância o sincronismo de liberação de energia e proteína no interior do rúmen, a fim de maximizar a fermentação ruminal e a produção de proteína microbiana. Segundo Theurer et al. (1999), o uso do milho floculado proporcionou maior fluxo de proteína microbiana para o duodeno, em média $18 \%$ maior nas vacas que foram alimentadas com milho floculado, comparadas àquelas alimentadas com milho quebrado. Neste sentido, maior atenção deve ser dada às dietas com milho floculado como principal fonte de energia. Lykos \& Varga (1995), em seus estudos in situ, reportaram maior solubilidade da fração protéica no milho moído fino (22,3\%) do que no floculado $(1,7 \%)$ e quebrado (7\%); a degradabilidade efetiva da proteína foi maior na moagem fina $(53,3 \%)$, seguida da quebra $(31,7 \%)$ e da floculação $(29,4 \%)$.

\section{Conclusão}

A floculação do milho melhora a utilização ruminal do amido do grão e diminui a da proteína.

\section{Agradecimentos}

Aos funcionários Everson Lázaro e Gilmar Botteon, pelo manejo dos animais; aos técnicos Ari de Castro, Gilson de Godoy e Simi Robassini, pela ajuda nas análises laboratoriais.

\section{Referências}

ASSOCIATION OF OFFICIAL ANALYTICAL CHEMISTS (Washington, Estados Unidos). Official methods of analysis. $13^{\text {th }}$ ed. Washington, 1985. 1141p.

CHEFTEL, C.; CUQ, J.L.; PROVANSAL, M.; BESANCON, P. Influence of processing on the composition and the nutritive value of protein foods. Review Forage and Crops Grassland, v.1, p.711, 1976.

CONE, J.W.; CLINE-THEIL, W.; MALESTEIN, A.; KLOOSTER, A.T. van. Degradation of starch by incubation with rumen fluid: a comparation of different starch sources. Journal of the Science of Food Agriculture, v.49, p.173-178, 1989.

CUMMINS, K.A.; NOCEK, J.E.; POLAN, C.E.; HERBEIN, J.H. Nitrogen degradability and microbial protein synthesis in calves fed diets of varying degradability by the bag technique. Journal of Dairy Science, v.66, p.2356-2364, 1983.

HENDRIX, D.L. Rapid extraction and analysis of nonstructural carbohydrates in plant tissues. Crop Science, v.33, p.1306-1311, 1993.

HERRERA-SALDANA, R.; GOMEZ-ALARCON, R.; TORABI, M.; HUBER, J.T. Influence of synchronizing protein and starch 
degradation in the rumen on nutrient utilization and microbial protein synthesis. Journal of Dairy Science, v.73, p.142-148, 1990.

KOTARSKI, S.F.; WANISKA, R.D.; THURN, K.K. Starch hydrolysis by the ruminal microflora. Journal of Nutrition, v.22, p.178-190, 1992.

LEE, S.Y.; KIM, W.Y.; KO, J.Y.; HA, J.K. Effects of corn processing on in vitro and in situ digestion of corn grain in Holstein steers. Australian Journal of Animal Science, v.15, p.851-858, 2002.

LYKOS, T.; VARGA, G. Effects of processing method on degradation characteristics of protein and carbohydrate sources in situ. Journal of Dairy Science, v.78, p.1789-1801, 1995.

McClEARY, B.V.; SOLAH, V.; GIBSON, T.S. Quantitative measurement of total starch in cereal flours and products. Journal of Cereal Science, v.20, p.51-58, 1994.

MEHRES, A.Z.; ØRSKOV, E.R. A study of the artificial fiber bag technique for determining the digestibility of feeds in the rumen. Journal of Agricultural Science, v.88, p.645-650, 1977.

NATIONAL RESEARCH COUNCIL. Nutriente requirements of dairy cattle. $6^{\text {th }}$ ed. Washington: National Academy of Science, 1989. $157 \mathrm{p}$.

ØRSKOV, E.R.; McDONALD, I. The estimation of protein degradability in the rumen from incubation measurements weighted according to rate of passage. Journal of Agricultural Science, v.92, p.499-503, 1979.

ØRSKOV, E.R.; HOVELL, F.D.D.; MOULD, F. Uso de la técnica de la bolsa de nylon para la avaluación de los alimentos. Production Animal Tropics, v.5, p.213-233, 1980.

OWENS, F.N.; ZINN, R.A.; KIM, Y.K. Limits to starch digestion in the ruminant small intestine. Journal of Animal Science, v.63, p.1634-1648, 1986.
PASSINI, R. Processamento de grãos de milho e de sorgo e níveis de proteína sobre a digestibilidade, desempenho e características de carcaça de bovinos superprecoces. 2001. 54p. Tese (Doutorado) - Universidade Estadual Paulista, Botucatu.

ROONEY, L.W.; PFLUGFELDER, R.L. Factors affecting starch digestibility with special emphasis on sorghum and corn. Journal of Animal Science, v.63, p.1607-1623, 1986.

ROSSI JÚNIOR, P.; PEREIRA, J.R.A. Manual prático de avaliação nutricional de alimentos. Piracicaba: Fealq, 1995. 34p.

SAS INSTITUTE (Cary, Estados Unidos). Statistical analysis system. $5^{\text {th }}$ ed. Cary, 1985. 890p.

SINDT, M.H.; STOCK, R.A.; KLOPFENSTEIN, T.J.; SHAIN, D.H. Effect of protein source and grain type on finishing calf performance and ruminal metabolism. Journal of Animal Science, v.71, p.1047-1056, 1993.

TEIXEIRA, J.C.; SANTOS, R.M.; OLIVEIRA, A.I.G. Degradabilidade ruminal da matéria seca, proteína bruta e fibra em detergente neutro de rações contendo caroço de algodão e grão de milho, em diferentes formas físicas, em vacas da raça Holandesa. Revista Brasileira de Zootecnia, v.25, p.814-823, 1996.

THEURER, C.B. Grain processing effects on starch utilization by ruminants. Journal of Animal Science, v.63, p.1649-1662, 1986.

THEURER, C.B.; HUBER, J.T.; DELGADO-ELORDUY, A.; WANDERLEY, R. Invited review: summary of steam-flaking corn or sorghum grain for lactating dairy cows. Journal of Dairy Science, v.82, p.1950-1959, 1999.

WADHWA, M.; DHARAM, P.; KATARIA, P.; BAKSHI, M.P.S. Effect of particle size of corn grains on the release of nutrients and in sacco degradability. Animal Feed Science Technology, v.72, p.1117,1998 . 